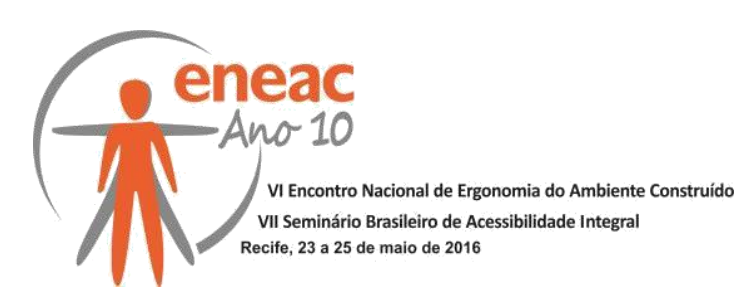

\title{
E AGORA? UMA METODOLOGIA PARA DISCUTIR O DESENHO UNIVERSAL EM PROJETOS PADRONIZADOS
}

\author{
BAPTISTA, Mariana Bertani (1); \\ SUMI, Camilla M. (2) \\ GEIA, Maíra (3) \\ GOMES, Thaís C.M. (4) \\ BERNARDI, Núbia (5) \\ KOWALTOWSKI, Doris C. C. K. (6) \\ (1) Universidade Estadual de Campinas, Mestranda. \\ e-mail: mariberbap@yahoo.com.br \\ (2) Universidade Estadual de Campinas, Mestranda \\ e-mail: camillasumi@gmail.com \\ (3) Arquiteta e Urbanista. \\ e-mail: malaurencageia@gmail.com \\ (4) Arquiteta e Urbanista. \\ e-mail: thais.arathais@gmail.com \\ (5) Universidade Estadual de Campinas, Doutora \\ e-mail : nubiab@fec.unicamp.br \\ (6) Universidade Estadual de Campinas, Profa. Titular \\ e-mail : doris@fec.unicamp.br
}

\begin{abstract}
RESUMO
Este artigo apresenta o resultado de um estudo de caso realizado com o intuito de descobrir como o processo participativo pode influenciar um projeto arquitetônico padrão. Após serem analisados os documentos pertinentes, foi desenhada uma metodologia de análise da acessibilidade dos projetos padronizados das creches Nave Mãe em Campinas/SP, e aplicada em uma edificação recéminaugurada. Com os dados obtidos foi elaborada uma dinâmica no formato de jogo de tabuleiro, intitulado "E agora?", que foi aplicada a profissionais de projeto. O resultado foi o apontamento de soluções, mostrando que num projeto institucional, a discussão entre usuários e profissionais minimizam futuros problemas.
\end{abstract}

Palavras chave: Metodologia de análise de projeto; Acessibilidade; Processo participativo. 


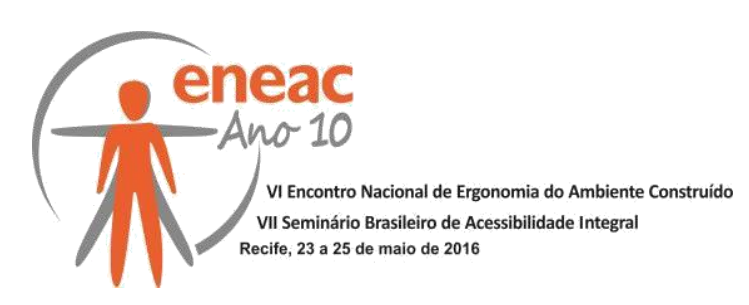

\begin{abstract}
This article presents the results of a case study performed in order to find out how the participatory process can influence a standard architectural design. After analysing relevant documents, it has been designed a method for accessibility analysis of the standard projects of nursery and kindergartens called Nave Mãe, in Campinas/SP, and applied in a brand-new building. With data was created a dynamic in the board game format, entitled 'Now What?' which was applied to design professionals.

The result was a notation of solutions, proving that for an institutional project, the discussion between users and design professionals can minimize future problems.
\end{abstract}

Keywords: Project analysis methodology; Accessibility; Participatory process.

\title{
1. INTRODUÇÃO
}

Segundo o Censo Demográfico de 2010, o Brasil possui 45 milhões de habitantes que apresentam alguma deficiência (IBGE, 2010). Neste contexto o Desenho Universal e seus Sete Conceitos - utilização equitativa, flexibilidade de utilização, utilização simples e intuitiva, informação perceptível, tolerância ao erro, esforço físico mínimo, dimensão e espaço de abordagem e de utilização - são de extrema importância tanto para a produção como para a adequação dos espaços construídos.

Sabendo-se que o objetivo do Desenho Universal é beneficiar simultaneamente todas as idades e capacidades (STORY, 2001), deve-se providenciar um ambiente de integração, que estabeleça formas comuns de vida, de aprendizagem e de trabalho entre pessoas deficientes e não deficientes. Tal integração requer a promoção das qualidades próprias do individuo, sem estigmatização e sem segregação (STEINEMANN, 1994).

Este artigo apresenta um relato sobre a atual arquitetura escolar em Campinas utilizando como pesquisa de campo uma creche da rede pública, cujo projeto arquitetônico é padronizado pela municipalidade e que atende às demandas de crianças com e sem deficiência. Assim, baseado no referencial teórico, identificou-se os métodos que possibilitassem uma investigação a partir dos dados coletados sobre as dificuldades enfrentadas por crianças e seus educadores/cuidadores na ambiente escolar.

Atualmente, a inclusão de pessoas com deficiência é um tema que evidencia a carência dos recursos que promovam a acessibilidade e ampliem as funcionalidades desses cidadãos. Neste sentido, há a necessidade de que os ambientes e produtos, principalmente aqueles utilizados por todos, sejam pensados para diferentes indivíduos, com limitações distintas, habilidades outras e potenciais diferenciados - ou seja, baseada nos sete princípios do Desenho Universal. Assim, começa a construção de uma sociedade mais inclusiva e com valores iguais para todas as pessoas. Desde os primeiros anos de vida deve-se oportunizar a integração de crianças com e sem deficiência, com o intuito delas conhecerem e vivenciarem as diferenças individuais de cada ser humano.

\section{OBJETIVO GERAL E OBJETIVOS ESPECÍFICOS}

O objetivo geral do trabalho foi analisar um projeto padronizado de arquitetura escolar, focando na análise da acessibilidade oferecida pela edificação. Para a realização deste 


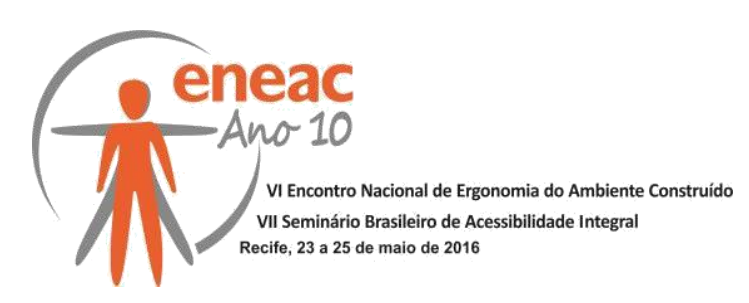

estudo de caso foram selecionados os projetos padronizados das creches Nave Mãe, na cidade de Campinas, interior de São Paulo.

O objetivo específico foi analisar o critério de acessibilidade para pessoas com deficiência locomotora, intelectual e múltipla, e se as soluções que foram padronizadas no projeto, desde as aberturas até a implantação, estavam de acordo com as necessidades destes usuários. A formulação de melhorias de projeto e de uma metodologia do processo de projeto escolar foram os objetivos específicos secundários da presente pesquisa.

\section{JUSTIFICATIVA}

Para aplicação dos objetivos foi escolhido para estudo de caso um projeto arquitetônico recente com foco na rede pública escolar no município de Campinas. O projeto selecionado - implantado em 2015 - uma Nave Mãe localizada em um bairro periférico na cidade, atende a um modelo de projeto educacional diferenciado, vindo a conciliar com o modelo tradicional existente. Esse modelo segue um projeto arquitetônico do renomado arquiteto João Filgueiras Lima, o Lelé, com elementos modernos e característicos próprios do arquiteto, sendo o projeto arquitetônico padronizado para toda a rede infantil.

\section{METODOLOGIA}

A metodologia incidiu em diversas etapas:

a) Análise de Referências da Literatura que incluiu: revisão bibliográfica; estudo de leis e normas sobre inclusão e acessibilidade como a NBR 9050, estudos científicos sobre acessibilidade, com ênfase nos métodos aplicados, dados estatísticos e soluções aplicáveis a projetos;

b) Busca de projetos arquitetônicos referenciais na temática escolar no Brasil e no mundo;

c) Análise da Nave Mãe: levantamento do histórico, contexto local, estudo sobre o arquiteto do projeto e leitura das plantas arquitetônicas;

d) Roteiro de avaliação: com base no levantamento físico-arquitetônico, observação dos usos, distribuição interna dos ambientes e rotas disponíveis, foi elaborado um walkthrough da creche: dos acessos, passando pelas salas de atividades, refeitório e playground. Também foi elaborado um check-list para a análise e observação de alguns elementos considerados importantes para a arquitetura escolar inclusiva;

e) Visita Técnica à Nave Mãe: foi realizada em uma unidade recém-inaugurada, a Nave Mãe Conceição Anita Mendes Ferreiro Girondo, localizada no bairro Jardim Ibirapuera. $\mathrm{Na}$ visita realizada, de caráter exploratório, a equipe foi estimulada a compreender $\mathrm{o}$ espaço apenas com as informações arquitetônicas e gráficas existentes. Ocorreu um passeio acompanhado (walkthrough) com a diretora da creche, e todo o percurso foi registrado com fotografias e anotações. Além disso, também foram aplicados

questionários e entrevistas. Esta primeira percepção da visita técnica foi complementada com o estudo detalhado das plantas arquitetônicas existentes, tanto da creche visitada quanto de outras creches do mesmo padrão, sendo possível identificar os usos e as possibilidades de percursos. Verificaram-se os problemas de 


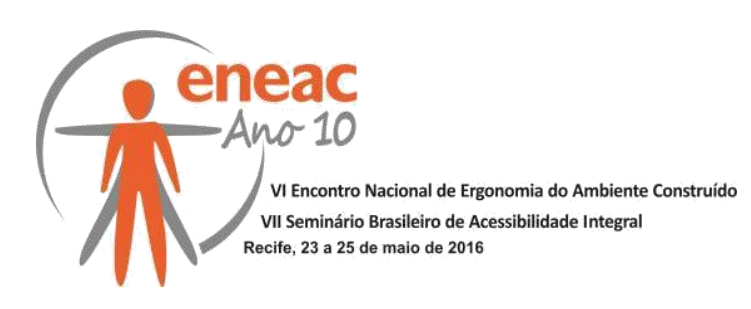

acessibilidade existentes na escola investigada, sob o ponto de vista do Roteiro de Avaliação;

f) Dinâmica: Com os dados colhidos na visita, foi elaborada uma dinâmica para ser experimentada com profissionais arquitetos. A dinâmica consistiu em um jogo de tabuleiro feito para ser aplicado a um Grupo Focal, ou seja, para ser aplicado a pequenos grupos de pessoas que em reunião avaliam os conceitos e situações, identificando os problemas existentes e que possam vir a existir.

g) Análise final: foi elaborada uma análise sobre a aplicação das metodologias estudadas e uma conclusão técnica sobre o projeto estudado e possíveis melhorias dentro do seu contexto, com o auxilio da dinâmica aplicada aos profissionais arquitetos.

\section{O ESTUDO DO PROJETO}

\subsection{O Projeto Padrão das Nave Mãe}

Um novo modelo de educação infantil foi implantado em 2007 no município de Campinas, $\mathrm{SP}$, para atender o déficit da demanda de crianças por creches e escolas infantis, o qual recebeu o nome de Nave Mãe. Diferentemente dos ensinos tradicionais, estas estruturas públicas são administradas por organizações não governamentais (ONGs) e por empresas privadas, que através dessas parcerias público-privadas, tem como principal objetivo a ampliação do número de vagas para crianças de 0 a 6 anos de idade.

Além disso, o projeto também visa oferecer cursos profissionalizantes, que possam gerar empregos para as mães dos alunos, assim, os lugares escolhidos para sediar as Naves Mãe, em sua maioria, devem atender aos critérios socioeconômicos de uma região carente, normalmente, instalados em bairros novos, formados por conjuntos habitacionais de interesse social ou em assentamentos informais, localizados na extrema periferia do município, como nos casos do Jardim Bassoli, Conjunto Habitacional Vida Nova, Jardim Marisa, entre outros.

Outro aspecto importante diz respeito à metodologia de ensino empregada, que difere dos modelos das creches e escolas infantis com a adoção da Pedagogia dos Sentidos, a qual aborda atividades pedagógicas desenvolvidas através de projetos criados em conjunto com professores e alunos, sem a utilização de disciplinas formais. Apesar desta proposta pedagógica apresentar uma maior liberdade de interação entre seus membros, o projeto arquitetônico das Naves Mãe são padronizados, como veremos adiante.

Na gestão municipal em que o projeto das Naves Mãe foi idealizado, o então prefeito, Dr. Hélio de Oliveira Santos, firmou uma parceria para este projeto com o arquiteto João Filgueiras Lima ${ }^{1}$, cujas assinaturas, também estão presentes em obras realizadas no ano de 2005, como o Comando de Ação Preventiva (CAP) da Guarda Municipal de Campinas e o Pronto Socorro do Campo Grande.

1 João Filgueiras Lima, nasceu no Rio de Janeiro em 1932 e formou-se em 1955 na Escola Nacional de Belas Artes, sua arquitetura foi caracterizada pela interação da arte e tecnologia. Dentre suas obras, as que destacam são o Hospital Sarah Kubitschek Salvador, o Memorial Darcy Ribeiro, a Igreja do Centro Administrativo da Bahia, entre outras. Fonte: CAU-BR, 22/05/2014. 




O projeto das Naves Mãe é composto por um único volume (Figura 1), apenas as áreas do playground e quadra poliesportiva são implantadas conforme as situações encontradas nos diferentes tipos de terrenos disponibilizados pela Prefeitura. É importante destacar que os projetos construídos não correspondem totalmente ao modelado por Lelé, devido a questões orçamentais, mas seus traços são evidentes no pátio central, composto por uma cobertura ondulada com iluminação natural, permeando de maneira sutil no interior da edificação.

As entradas são separadas em duas: a primeira para pedestres, isto é, os pais e as crianças, a segunda voltada para o estacionamento, dá acesso às áreas administrativas, como a secretaria, a sala de professores e a diretoria. Entretanto, conforme adiante, nem todas as implantações estão dispostas dessa forma. Já a circulação interna obedece ao pátio central de forma retangular, lugar de onde partem os corredores para as salas de agrupamento, destinadas às atividades pedagógicas, as salas multiuso, que com um tamanho maior podem oferecer outras atividades no período, os banheiros e os lactários, destinados às crianças mais novas. Nesta mesma área central, está ligado diretamente o refeitório, que por sua vez, conecta-se com a cozinha e com a lavanderia, o palco teatral instalado na perpendicular do lado maior do retângulo, também é o espaço em que estão os brinquedos de médio porte, funcionando até mesmo como um grande playground coberto.

Quando a Nave Mãe pode ser ampliada, há mais salas de agrupamento e uma quadra poliesportiva, a imagem abaixo mostra uma edificação completa, o padrão utilizado pelas demais, salvo exceções, que normalmente estão relacionadas com 0 terreno de implantação.

Figura 1: Planta da CEI Nave Mãe Prof. José Aristodemo Pinotti.

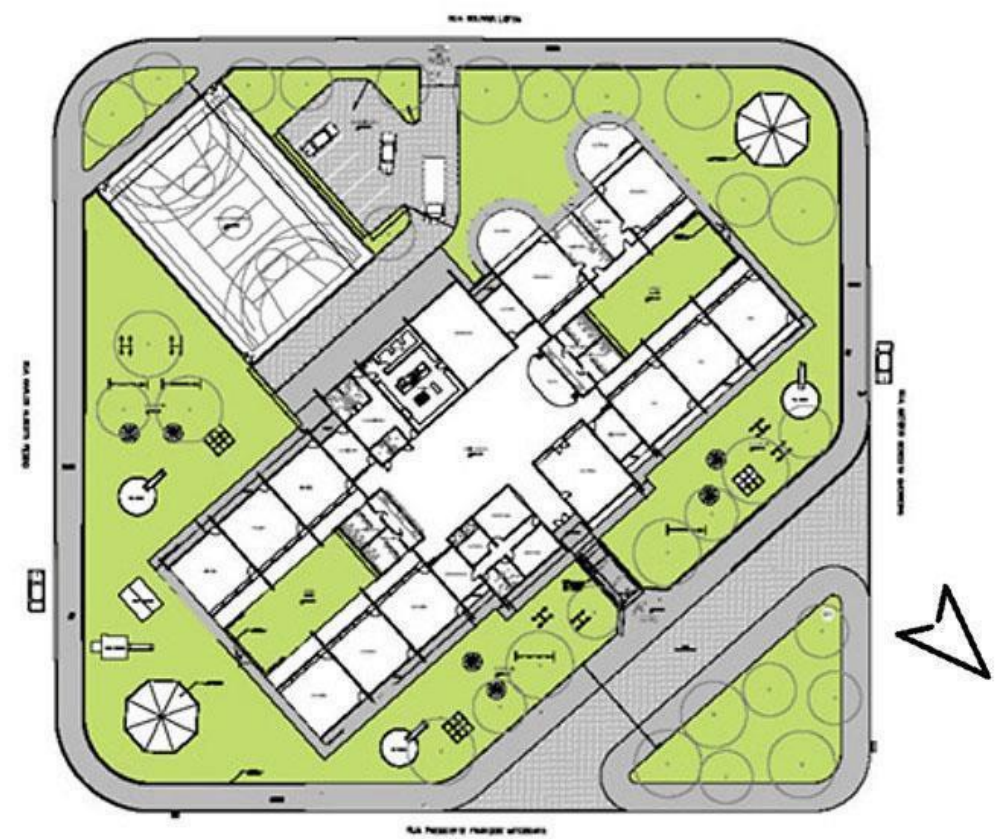

Fonte: http://www.chance.org.br/?page id=371http:///hhttp:///h 


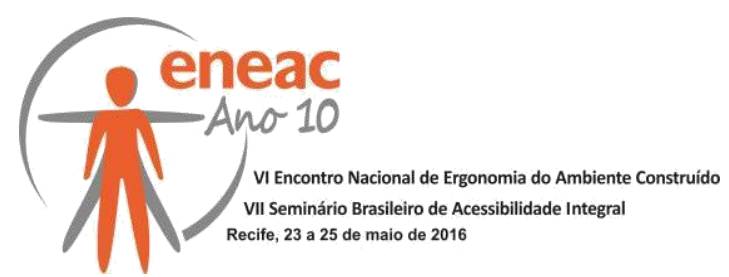

\subsection{A Nave Mãe Visitada: CEI Nave Mãe Conceição Anita Mendes Ferreiro Girondo}

A Nave Mãe visitada, inaugurada em julho de 2015, e em funcionamento desde agosto do mesmo ano, localiza-se no Jardim Ibirapuera em Campinas, e está próxima ao shopping Parque das Bandeiras, a maternidade Celso Pierro, ao Campus II da Pontifícia Universidade Católica de Campinas e da Av. John Boyd Dunlop (Figura 2). Os elementos que caracterizam o bairro recém-formado são moradias unifamiliares de até dois pavimentos.

Com a formação da primeira turma de crianças no segundo semestre de 2015, o mesmo semestre letivo da visita, não houve matriculas para todas as vagas oferecidas, muito menos houve uma demanda específica de crianças com alguma deficiência.

O terreno de sua implantação apresenta um grande declive (Figura 3 e 4), que acabou por gerar alguns impactos negativos quanto a proposta inicial do projeto padrão. É notória a imensa quantidade de terra removida para a instalação da edificação em um único platô, entretanto, há outro platô inferior em que está o playground, o qual possui uma única rampa de acesso, com declividade acima do permitido pela NBR 9050 (Figuras 5 e 6).

Figuras 2, 3 e 4: No sentido horário: Implantação; Volumetria da Nave Mãe, detalhe para o portão de pedestres e reservatório; Entrada principal, voltada a divisa do terreno.


Fonte: Google Earth, 2015 e levantamento fotográfico das autoras. 


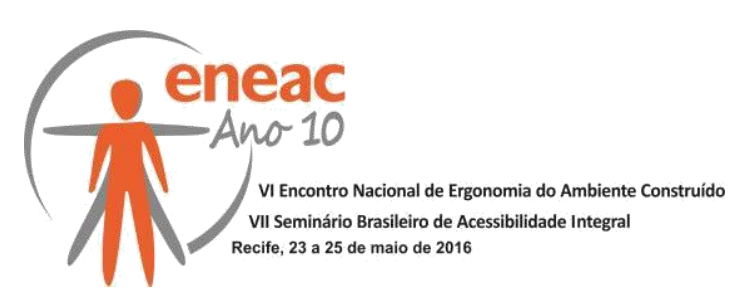

Figuras 5 e 6: Acesso ao playground, terminação da rampa na grama.
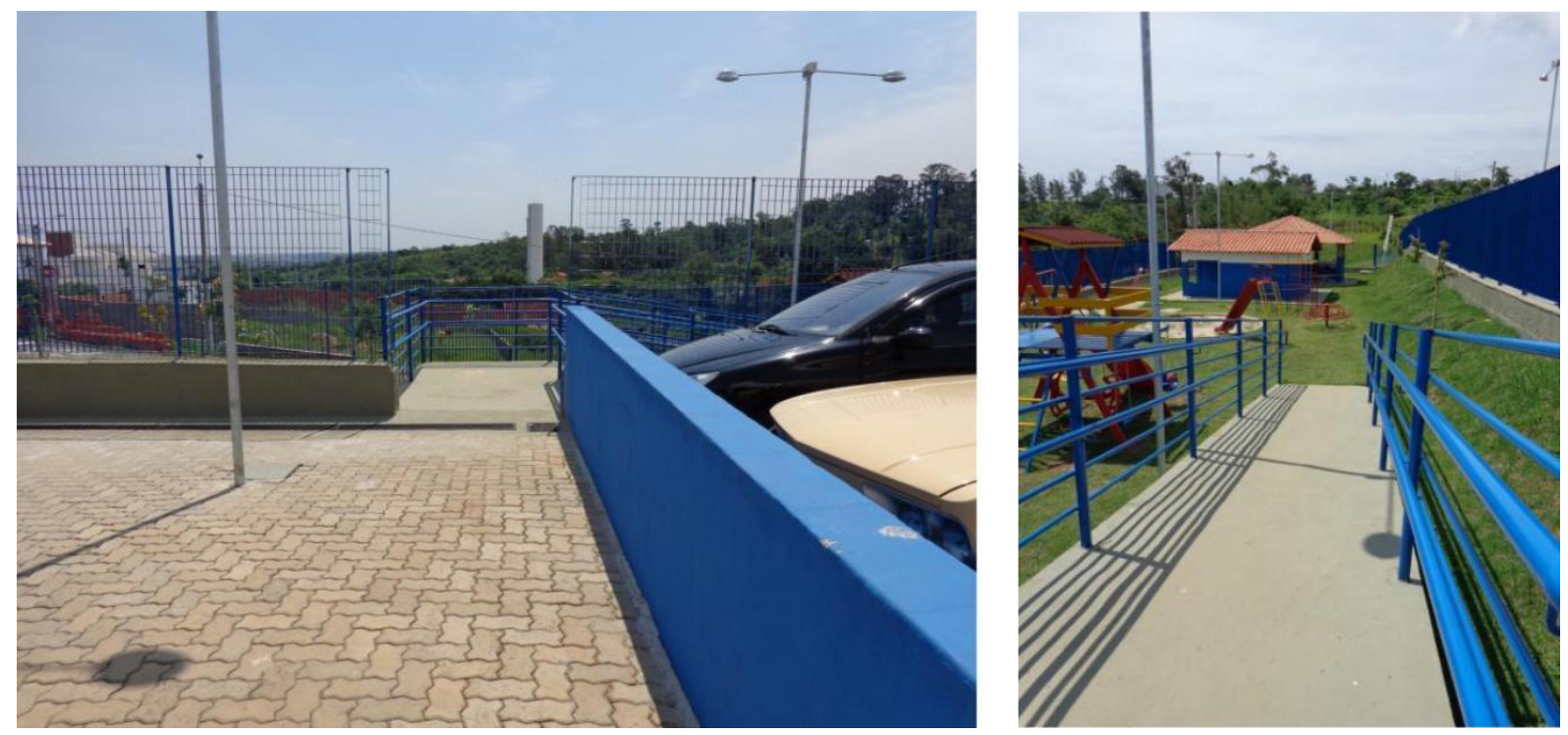

Fonte: levantamento fotográfico das autoras.

Ao entrar na edificação logo se percebe uma incoerência, pois a entrada da Nave Mãe torna-se pouco convidativa e constrangedora para os pais e funcionários, pois há apenas duas opções de acesso imediato: a primeira localizada em frente ao reservatório e a segunda, junto ao estacionamento, pela cozinha e vestiários dos funcionários ou pela porta da lavanderia. Isso se deve ao padrão do projeto, que não permite uma articulação no próprio programa arquitetônico, pois há um "travamento" no desenho dos ambientes internos e o pátio central, o que neste caso, complicou-se com um terreno íngreme.

Outro detalhe importante é em relação à orientação solar. Por possuir um volume único linear, seria mais adequada uma implantação norte-sul e não leste-oeste, como o ocorrido, até mesmo porque os agrupamentos infantis estão dispostos nos dois lados destas fachadas, as quais são prejudicadas com ofuscamento direto e retenção de calor, no período da manhã e, principalmente, à tarde.

Quanto à distribuição interna dos ambientes há uma sincronia e proximidade das atividades, como a cozinha e o refeitório, a salas dos professores com a direção, a suposta entrada principal com a secretaria, e os agrupamentos ao lactário, todas indicadas apenas visualmente com o nome do ambiente, e, sem nenhuma sinalização tátil de alerta e direcional.

Em todos os ambientes foram utilizados pisos cerâmicos com textura, provavelmente devido ao seu baixo custo de instalação e manutenção, mas deve-se atentar para os riscos quanto à segurança, principalmente, para as áreas em que bebês e crianças costumam ficar no chão ou engatinhar. 


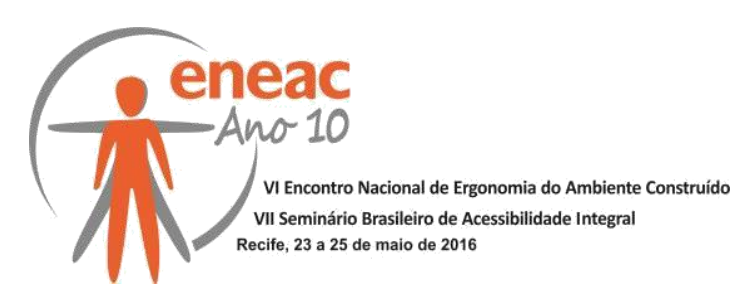

\section{APLICAÇÃO DE UMA METODOLOGIA: CRIANDO UMA DINÂMICA}

Os resultados das metodologias aplicadas - walkthrough, entrevistas, fotografias, check-lists e questionários - conduziu o levantamento dos problemas relacionados à acessibilidade espacial, mobillidade, orientabilidade e segurança das crianças do Centro de Educação Infantil Nave Mãe Conceição Anita Mendes Ferreiro Girondo. Com o levantamento destes problemas técnicos em mãos foi pensada uma dinâmica que estimulasse os projetistas a ampliar o olhar sobre o projeto, pensando nas necessidades específicas das crianças e sugerindo melhorias que pudessem sanar, ou ao menos amenizar os problemas encontrados, principalmente aqueles relacionados aos conceitos do Desenho Universal. A dinâmica, denominada „E agora?" foi feita no formato de jogo de tabuleiro, como método de análise do projeto escolar padronizado, utilizando a técnica de grupo focal.

\subsection{Apresentação do jogo "E agora?": objetivos}

O objetivo do jogo "E agora?" é despertar nos jogadores a criatividade para solução de problemas de acessibilidade e mobilidade dentro do Centro de Educação Infantil Nave Mãe Conceição Anita Mendes Ferreiro Girondo. Este jogo pode ser adaptado a outras escolas, ao se alterarem as plantas e as situações/problemas específicas.

Foram criadas regras para a realização dos objetivos pretendidos, no qual se sorteia os personagens de forma cega e arruma-se o tabuleiro com as cartas em seus respectivos lugares. Cada jogador se acomoda junto a sua respectiva faixa de ação no tabuleiro, e se familiariza com o seu ponto de ação, tanto pela foto do lugar como pela planta da creche Nave Mãe Conceição Anita Mendes Ferreiro Girondo localizada no centro do tabuleiro. Em cada dupla haverá dois personagens - um professor e um aluno - a jogada Inicial é a do professor, seguido pela jogada do aluno. Cada jogador em seu turno só poderá receber ajuda de seu respectivo colega aluno/professor. É interessante considerar a personalidade e idade de cada jogador para desenvolver a solução, quando for possível. Os jogadores se distribuem e agem conforme as Regras apontadas no item 6.2, e no fim da rodada única, ganhará a dupla que conjuntamente obtiver o maior número de estrelas.

\section{2 “E agora?": O jogo}

Ao iniciar o jogo é distribuído um material específico ao grupo de participantes (Figuras 7 e 8):

- 1 tabuleiro contendo a planta da escola.

- 8 pinos para jogo de tabuleiro

- 8 cartas personagens - 4 professores e 4 alunos

- 8 cartas situação problema - 1 para cada personagem

- 8 cartas de solução 'uma estrela' - 1 para cada personagem

- 8 cartas de solução 'três estrelas' - 1 para cada personagem

- 8 cartas de solução 'cinco estrelas' - 1 para cada personagem

- folhas de papel vegetal ou manteiga

- 8 fotos reais dos lugares problema

- 8 croquis - um para cada carta 5 estrelas. 


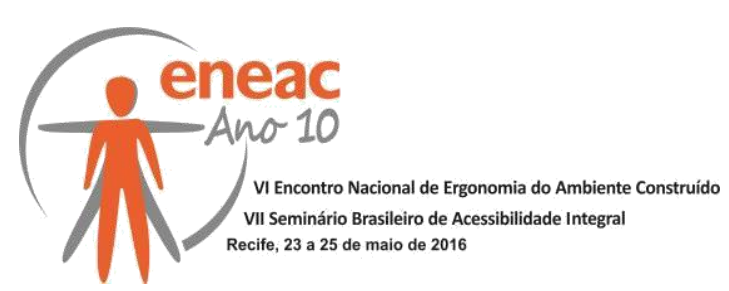

Figura 7: Tabuleiro desenvolvido para a dinâmica. Fonte: os autores.

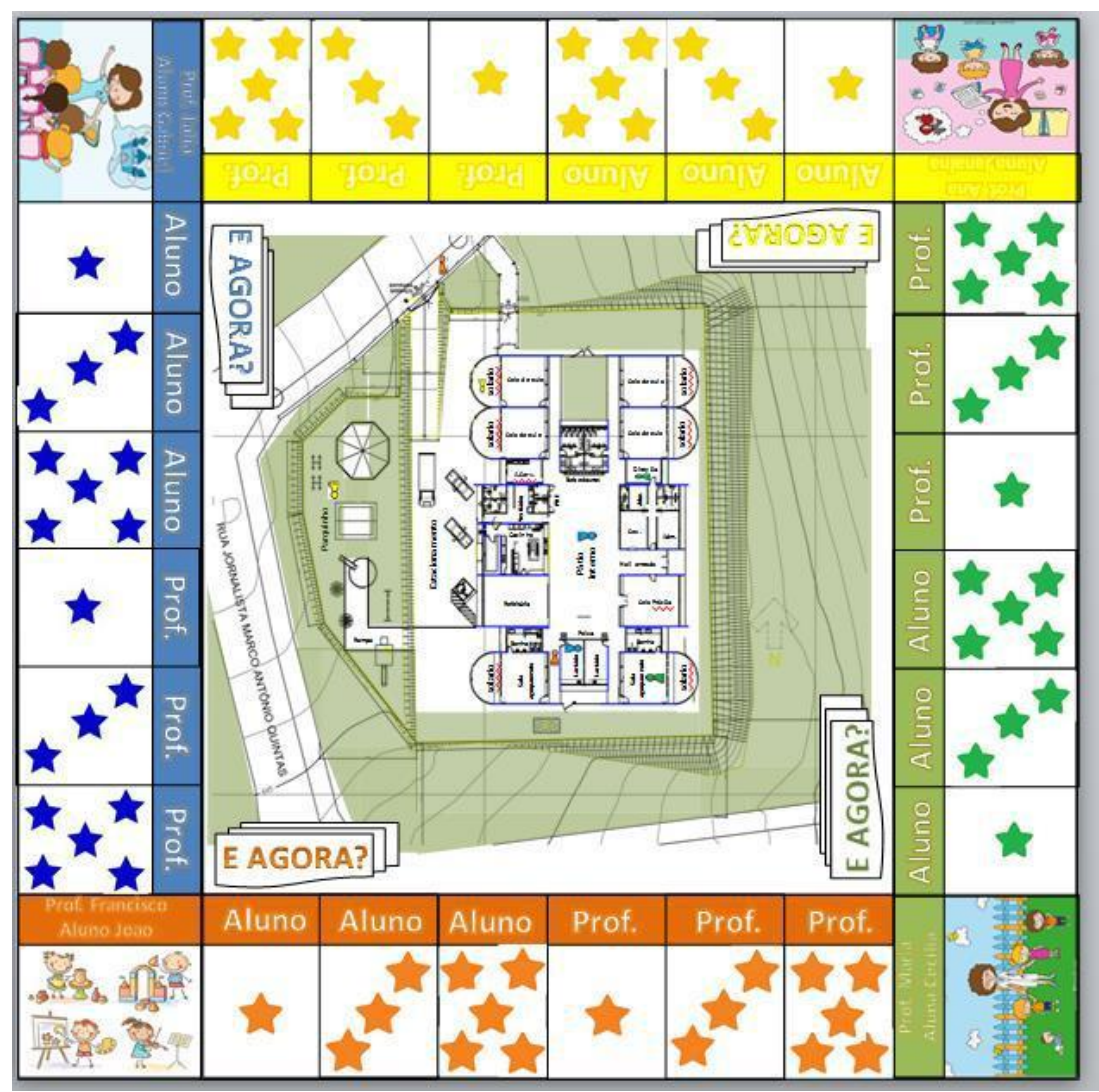

Figura 8: Cartas para a dinâmica e detalhes. Legenda: 1 - fotos reais dos lugares problema; 2 cartas de personagens; 3 - Cartas problema; 4 - Cartas solução uma estrela; 5 - Cartas solução três estrelas; 6 - Cartas solução cinco estrelas; 7 - Croquis das soluções cinco estrelas.
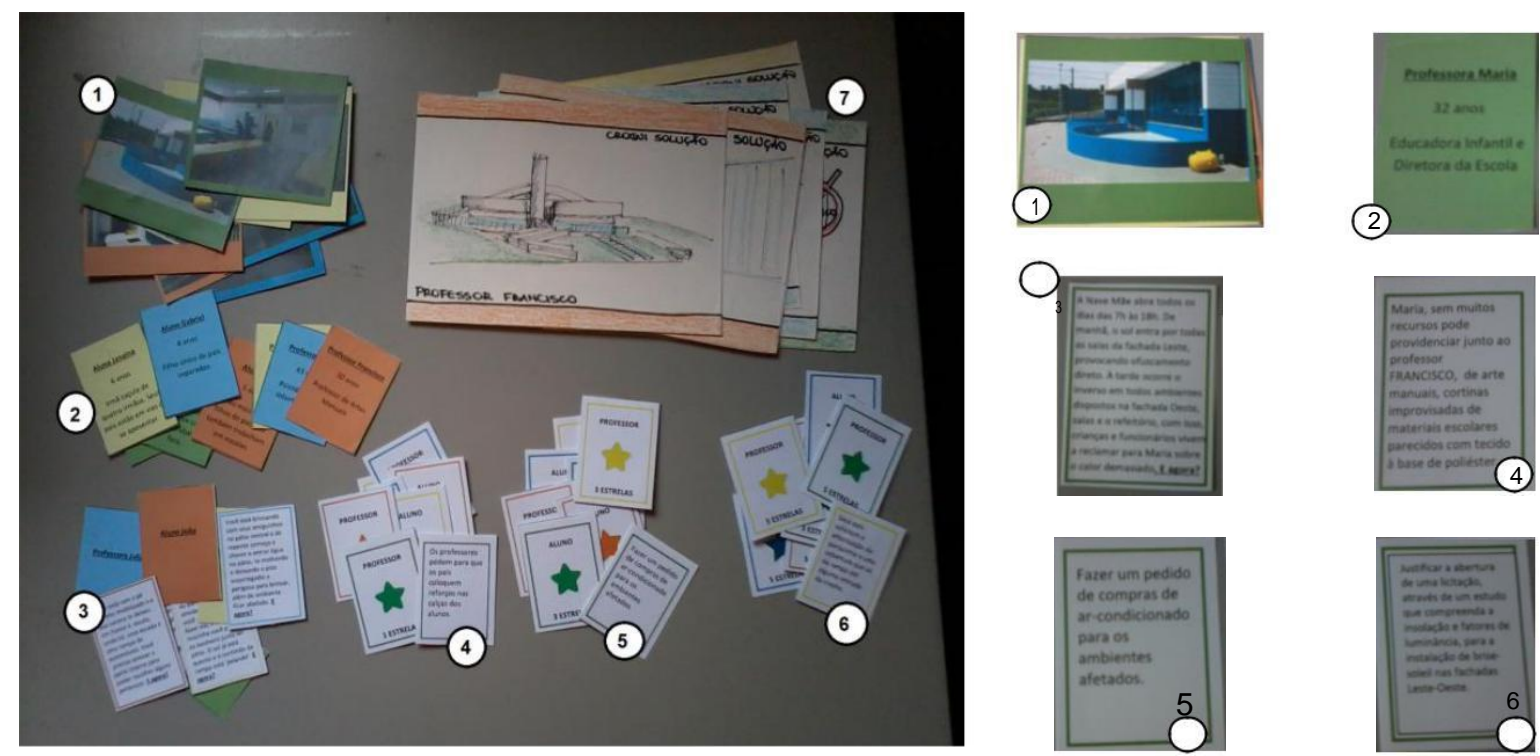

Fonte das Figuras 7 e 8: as autoras. 


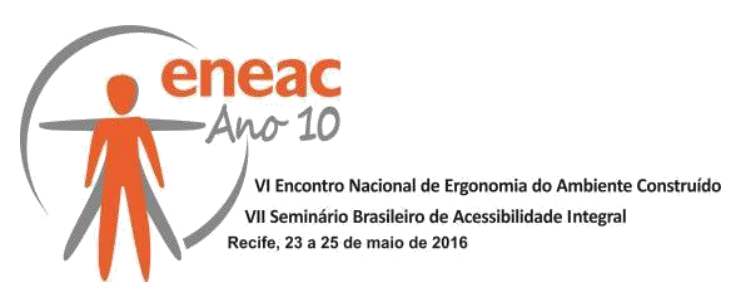

$\underline{\text { Regras do Jogo: }}$

- Sorteiam-se os personagens de forma cega. O tabuleiro deve estar arrumado com as cartas em seus respectivos lugares.

- Cada jogador se acomoda junto a sua respectiva faixa de ação no tabuleiro, e se familiariza com o seu ponto de ação, tanto pela foto do lugar como pela planta da creche Nave Mãe Conceição Anita Mendes Ferreiro Girondo localizada no centro do tabuleiro.

- Em cada dupla a jogada Inicial é a do professor, seguido pela jogada do aluno.

- Cada jogador em seu turno só poderá receber ajuda de seu respectivo colega aluno/professor. É interessante considerar a personalidade e idade de cada jogador para desenvolver a solução, quando for possível. O jogador começa a sua jogada retirando a sua carta problema e lendo a situação em que seu personagem se encontra. Então ele tem até 3 minutos para apontar uma solução.

- Apontada a solução podem ser viradas as cartas solução, uma a uma, em ordem crescente de valor em estrelas. Então se compara a solução proposta com as cartas e a pontuação em estrelas é dada através da comparação proposta-solução.

- Caso a solução proposta seja superior à solução 5 estrelas apontada pelas cartas, o jogador ganha 6 estrelas. No final da rodada, ganhará a dupla que conjuntamente obtiver o maior número de estrelas.

\section{A DINÂMICA NA PRÁTICA - RESULTADOS}

A dinâmica „E agora?" foi aplicada a um grupo de 07 arquitetos e 01 engenheiro civil (Figura 9) divididos em quatro duplas que, após receber a carta/situação problema, cada qual em sua rodada propôs as soluções que a seu ver melhor atenderiam à resolução do problema dado.

Figuras 9, 10 e 11: Participantes durante a realização da dinâmica, tabuleiro em uso.
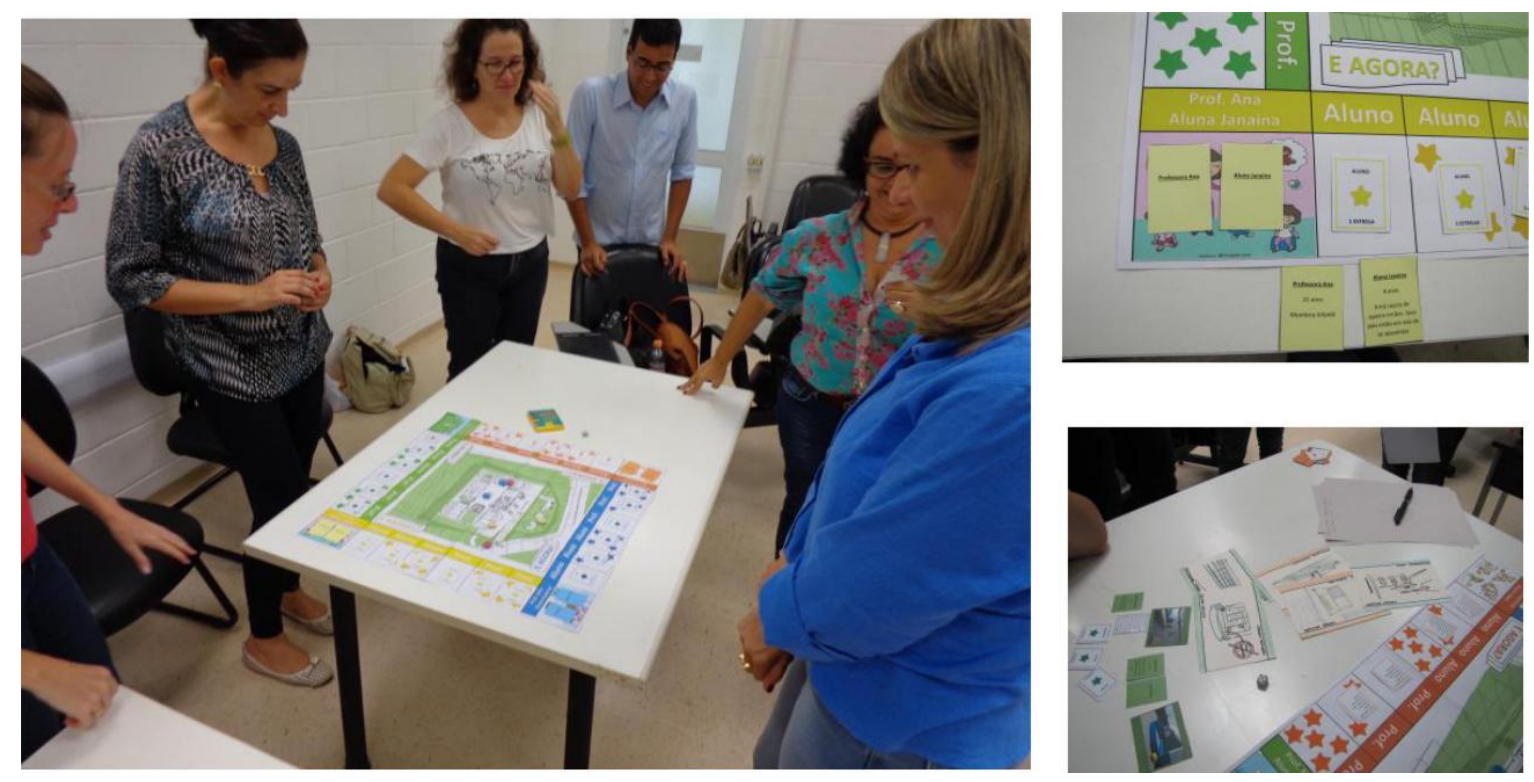

Fonte: levantamento fotográfico das autoras. 


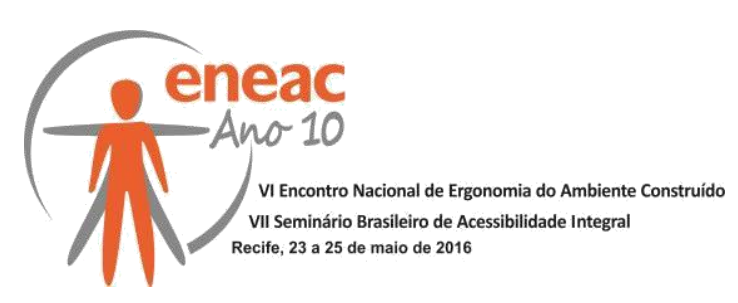

A primeira dupla, cujas situações problema eram a grande insolação recebida nas fachadas Leste-Oeste e o revestimento cerâmico áspero e frio nas salas dos bebês, propôs a instalação de brise-soleil e a troca do piso por revestimento vinílico. Além disso, a dupla também propôs a utilização de uma persiana perfurada que permite a ventilação e iluminação sem ofuscar e aquecer o ambiente, e a utilização de canos com água aquecida por energia solar sobrepostos às paredes, que serviriam para aquecer os berçários no inverno. A primeira dupla conseguiu 11 estrelas.

A segunda dupla tinha como situações problema o estar com uma perna imobilizada e precisar acessar o prédio estando na calçada, e o enxergar pelo visor de uma porta sendo uma criança de 4 anos de idade. As soluções apontadas foram a construção de uma rampa de acesso, a instalação de um visor vertical nas portas, que permitisse a visualização de uma criança, e a instalação de câmeras no parquinho com as imagens projetadas numa TV localizada no pátio. Por atender exatamente aos resultados esperados, a dupla obteve 10 estrelas.

A terceira dupla teve como problemas o transitar no pátio cheio de crianças carregando papinhas quentes, e o mesmo pátio com goteiras e abafado durante uma chuva. As soluções propostas foram a integração dos lactários e a instalação de tanques em uma área estratégica do pátio, encurtando a distância a ser percorrida, e a substituição da cobertura por uma estrutura em „escamas" permitindo ventilação e iluminação com o mínimo risco de chuva (referência: Arena do Morro, Natal/RN - Herzog e De Meuron). A dupla conseguiu 12 estrelas por apresentar duas soluções superiores às esperadas.

A última dupla deveria resolver os problemas de: no solário, manter as crianças sem acesso visual ao portão de entrada e saída, e no parquinho, como acessar o sanitário. As soluções propostas também foram superiores. Foi proposta uma parede verde no solário, dificultando a visualização externa, colaborando com 0 conforto térmico e estimulando 0 desenvolvimento sensorial das crianças. No parquinho a proposta foi a de instalar um sanitário PNE na estrutura de quiosque existente. Esta dupla obteve 13 estrelas.

Visto que a maior pontuação esperada era a de 10 estrelas por dupla, todas as respostas foram satisfatórias, e as pontuações obtidas denotaram que em 3 das 4 duplas, houve a proposição de soluções mais eficientes do que as esperadas. Em porcentagem, tivemos $25 \%$ das soluções dentro do esperado e $75 \%$ das soluções superiores ao esperado.

\section{CONCLUSÕES}

Com o auxilio das visitas e da aplicação da dinâmica, foi possível aferir que a troca de informações entre os usuários e um grupo de profissionais é imprescindível para a realização e a implantação de um bom projeto. A correta preparação de um programa de necessidades é capaz de minimizar os problemas de uso do ambiente construído e a dinâmica aqui proposta mostrou-se uma ferramenta bastante útil para a discussão de projeto.

O formato de jogo descontrai o participante, fazendo com que ele participe com uma melhor desenvoltura do que se estivesse participando de uma pesquisa formal, além disso, o jogo estimula a criatividade do participante de uma maneira muitas vezes surpreendente, gerando soluções melhores do que as esperadas no momento da confecção da dinâmica. 




Desde modo, o jogo „E agora?" pode auxiliar a concepção de projetos, padronizados ou não, realizados através de processos participativos entre profissionais da instituição e profissionais de projeto. $O$ resultado pode gerar um processo de projeto critico, discutindo com maior aprofundamento as questões da acessibilidade e do Desenho Universal.

\section{REFERÊNCIAS BIBLIOGRAFICAS}

IBGE. Censo Demográfico de 2010. Disponível em:

http://www.ibge.gov.br/home/estatistica/populacao/censo2010/default.shtm . Acesso em outubro/2015.http://outubro/2015

STEINEMANN, C.F. The Vocational Integration of the Handicapped. In EASE Edition nㅇ - pp.6 13. Vários (1994). Necessidades Educativas Especiais.

STORY, M.F. Principles of Universal Design in PREISER, W.F.E.; OSTROFF, E (ed). Universal Design Handbook. New York: Mc-Graw-Hill, 2001.

\section{BIBLIOGRAFIA CONSULTADA}

ARIAS, Camila Ramos; BIANCHI, Giovana; PINA, Silvia Mikami G.; KOWALTOWSKI, Doris C.K.K. e LABAKI, Lucila. Avaliando sentidos: espaços para surdocegos e múltiplo deficiente. IX Encontro Nacional e V Latino Americano de Conforto no Ambiente Construído, 2007.

BINS, Vera Helena Moro; DISCHINGER, Marta; LUZ, Greyce Kelly; BRANDÃO, Milena de. Mesquita. Acessibilidade Espacial e Inclusão nas Instalações do Colégio de Aplicação da Universidade Federal de Santa Catarina - Avaliação e Propostas de Projeto. Florianópolis, PET -UFSC, 2007.

CARNEIRO,.Rosângela Maria de Souza; DISCHINGER Marta. A cor na sala de aula do ensino médio: resultado de pesquisa realizada em escolas de Florianópolis. Periódico: 14은 Congresso Internacional de Ergonomia Sustentabilidade de Interfaces Humano- Tecnologia: Produto, Informações, Ambiente Construído e Transporte, Joinville: UFSC, 2014.

MESQUITA, Samara Annuar Haddad. Um Pouco da História das Creches e Naves-Mãe de Campinas: Paralelas Que Se Cruzam. TCC: Pedagogia da Faculdade de Educação da Universidade Estadual de Campinas, Orientação: Prof. Dr. José Luis Sanfelice. Campinas: UNICAMP, 2012

MULLER, Marcelle Suzete; BATISTA, Vilson João; TEIXEIRA, Fábio Gonçalves. Aplicação de metodologia ergonômica para ambiente construído na análise da acessibilidade em parques infantis. Periódico: $14^{\circ}$ Congresso Internacional de Ergonomia Sustentabilidade de Interfaces Humano- Tecnologia: Produto, Informações, Ambiente Construído e Transporte, Joinville: UFSC, 2014.

ORNSTEIN, Sheila Walbe (Org.); ALMEIDA PRADO, Adriana Romeiro de (Org.); LOPES, Maria Elisabete (Org.). Desenho Universal - caminhos da acessibilidade no Brasil. São Paulo: Annablume, 2010.

Visita técnica realizada em 12/11/2015 - Registro fotográfico das autoras, respostas a entrevistas e observações. 